\title{
Deep hypothermic circulatory arrest for resection of a right atrial accessory hepatic lobe
}

Alex M. D’Angelo, MD, ${ }^{a}$ Benjamin S. van Boxtel, MD, ${ }^{\mathrm{a}}$ Isaac Y. Wu, MD, ${ }^{\mathrm{b}}$ and Craig R. Smith, MD, ${ }^{\mathrm{a}}$ New York, NY

From the ${ }^{\mathrm{a}}$ Division of Cardiac, Vascular, and Thoracic Surgery, Department of Surgery, Columbia University Medical Center, New York, NY; and ${ }^{\mathrm{b}}$ Division of Cardiothoracic Anesthesia, Department of Anesthesiology, Columbia University Medical Center, New York, NY.

No funding was provided for this case report.

Disclosures: Authors have nothing to disclose with regard to commercial support.

Received for publication Feb 10, 2019; revisions received March 16, 2019; accepted for publication March 20, 2019; available ahead of print April 24, 2019.

Address for reprints: Alex M. D'Angelo, MD, 177 Fort Washington Ave, MHB-7SK, New York, NY 10032

(E-mail: ad3403@cumc.columbia.edu).

J Thorac Cardiovasc Surg 2019;158:e101-2

$0022-5223 / \$ 36.00$

Copyright (C) 2019 by The American Association for Thoracic Surgery

https://doi.org/10.1016/j.jtcvs.2019.03.076

The most common right atrial (RA) tumors are benign myxomas, followed by sarcomas. Ectopic hepatic tissue is rare, but when encountered is most often found in the abdomen. Hepatic tissue in the RA is extremely uncommon, with only a handful of case reports in the literature. ${ }^{1}$ Here we report the finding of a large accessory hepatic tumor, which required deep hypothermic circulatory arrest for complete resection.

\section{CLINICAL COURSE}

A 53-year-old African American man with an incidentally discovered RA mass was referred for surgery. Medical history included antiphospholipid antibody syndrome and a submassive pulmonary embolus 2 years previously, which had been managed with anticoagulation. At that time, transthoracic echocardiography had revealed a $3 \times 3-\mathrm{cm}$ RA mass (Figure 1, $A$ ). The patient was unavailable for surgical follow-up in the interim, but ultimately he presented to the clinic at the request of his cardiologist. On the basis of imaging characteristics on multiple preoperative echocardiograms, including the presence of a discrete connecting stalk, the mass was considered to be most likely to be a myxoma.

Intraoperative transesophageal echocardiography (Figure $1, B$ ) showed a $3.5 \times 2.5-\mathrm{cm}$ mass attached at the junction of the RA and the inferior vena cava (IVC), with extension medially into the IVC. A median sternotomy was performed. The superior vena cava was cannulated directly, while the IVC was cannulated through the right femoral vein. The mass, however, extended too distally into the IVC to be safely removed while the patient was on bypass. The patient was rapidly cooled for 30 minutes to $17^{\circ} \mathrm{C}$ and, circulation was arrested. On spontaneous fibrillation of the heart, the aortic crossclamp was applied,

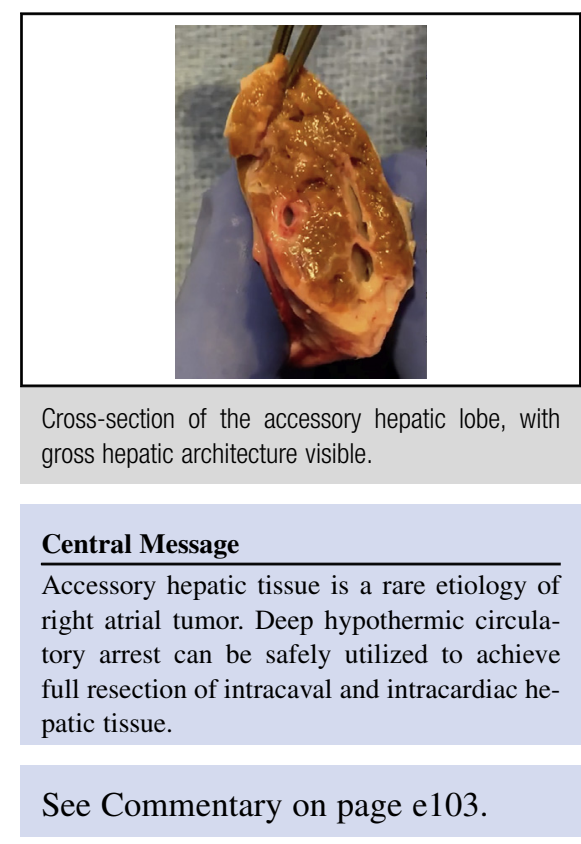

and cardioplegia was delivered. Resection was begun at junction of the IVC and the RA, where a clear isthmus attached the tumor. Resection extended into the medial IVC, where any semblance of a stalk was lost. The base of the mass was adjacent to 2 normal-appearing hepatic veins, which were spared, and normal hepatic parenchyma was entered to complete the resection. A CorMatrix patch (CorMatrix Cardiovascular Inc, Sunnyvale, Calif) was sewn to cover the liver defect and reconstruct the resected IVC. A second patch was used to close the anterior IVC into the RA, and it joined the previous patch at the diaphragm. Systemic flow was reestablished after 46 minutes of circulatory arrest. Final pathologic examination revealed unremarkable hepatic parenchyma (Figure 2).

The patient progressed well postoperatively, and he was discharged home 1 week after surgery.

\section{DISCUSSION}

On routine workup, ectopic hepatic tissue can be indistinguishable from more common types of atrial tumor. ${ }^{1}$ Our patient had no characteristics on preoperative imaging studies to suggest hepatic tissue. The patient's mass can be characterized as accessory hepatic tissue, because it maintained a connection to the native liver parenchyma. ${ }^{2}$ Ectopic liver is diagnosed when no connection exists. 


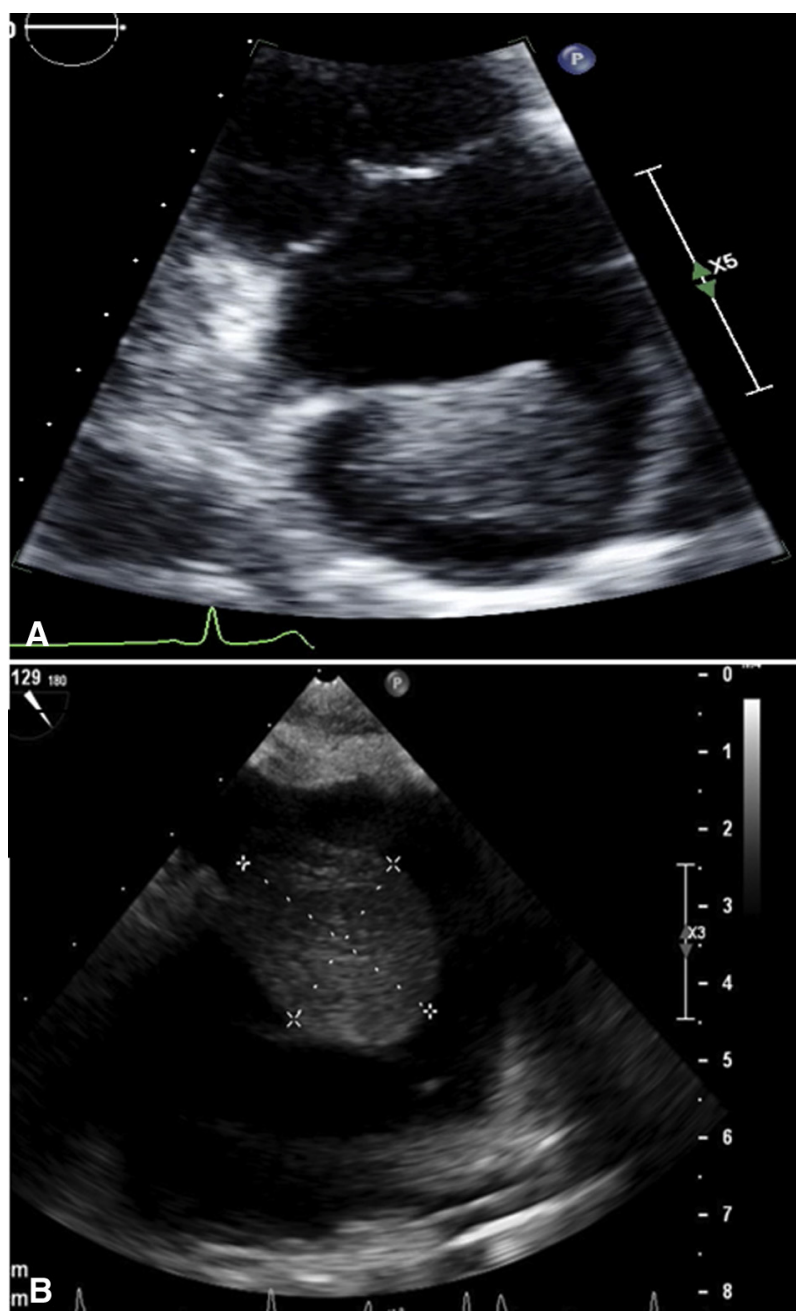

FIGURE 1. A, Preoperative transthoracic echocardiographic image with pedunculated mass present within the right atrium. B, Intraoperative transesophageal echocardiographic image with mobile mass at the junction of the right atrium and the inferior vena cava, with no visible extension into the inferior vena cava.

Ectopic liver has a reported incidence of less than $0.5 \%$ and is most often present near the gallbladder or spleen, or implanted on the peritoneum. ${ }^{3}$ The incidence of accessory liver lobe is less than $0.1 \%{ }^{3}$ There is only a single other documented case of true accessory hepatic lobe presenting solely as an RA mass, with no suggestion of IVC extension on preoperative imaging. ${ }^{4}$

The use of deep hypothermic circulatory arrest in the resection of this rare anomaly has not previously been reported in the literature. Most RA tumors have minimal IVC component and are able to be resected with standard bicaval venous cannulation. Because this patient's mass had a direct connection to the liver, however, we were unable to snare the IVC while maintaining the entire mass in the surgical field. Deep hypothermic circulatory arrest
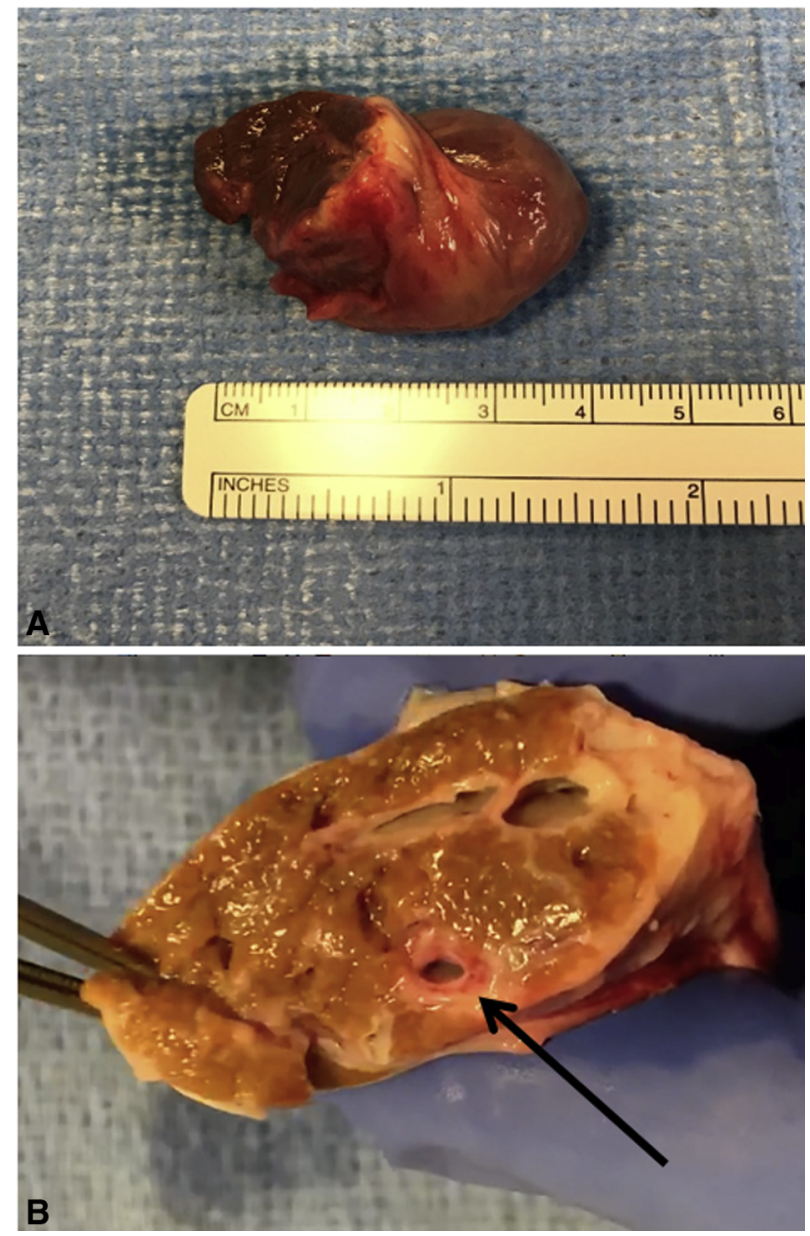

FIGURE 2. A, Gross appearance of the resected inferior vena cava and hepatic tumor. B, Tumor margin with notable sinusoidal architecture (arrow), suggestive of hepatic tissue at the time of resection.

allowed the complete visualization of the IVC toward the hepatic veins and also enabled a swift and complete resection.

\section{CONCLUSIONS}

Accessory hepatic tissue is a rare etiology of RA tumor. Deep hypothermic circulatory arrest can be used safely and effectively in these cases to achieve full resection of intracaval and intracardiac hepatic tissue.

\section{References}

1. Ansar-Gilan K, Jenkins T, Landeras L, Xin W, Rajiah P. Multimodality imaging of an unusual case of an obstructive intracaval mass by an aberrant liver. Circulation. 2015; 125:e310-2.

2. Moody WE, Hübscher SG, Rooney SJ, Doshi SN. Intracardiac ectopic liver mimicking atrial myxoma - an unusual cause for a right atrial mass. Int J Cardiol. 2016;209:210-2.

3. Trocciola SM, Balsam LB, Yee H, Gianos E, Srichai MB, DeAnda A Jr. Ectopic liver: an unexpected finding in a right atrial mass. Ann Thorac Surg. 2011;92: 715-8.

4. Chapman-Fredricks J, Birusingh R, Ricci M, Rodriguez M. Intracaval liver with cardiac extension. A new developmental anomaly? Fetal Pediatr Pathol. 2010; 29:401-6. 